\title{
Reproductive System Abnormalities in Schistosoma mansoni Adult Worms Isolated from Nectomys squamipes (Muridae: Sigmodontinae): Brightfield and Confocal Laser Scanning Microscopy Analysis
}

\author{
Renata Heisler Neves, Michele Costa-Silva, Elaine Machado Martinez, \\ Carla de Lamare Biolchini, Henrique Leonel Lenzi ${ }^{+++}$, Delir Corrêa Gomes**/++, \\ José Roberto Machado-Silva/ ${ }^{+} /++$
}

Departamento de Patologia e Laboratórios, Faculdade de Ciências Médicas, Universidade do Estado do Rio de Janeiro, Av. 28 de Setembro, 87 fundos, $5^{\circ}$ andar, 20551-031 Rio de Janeiro, RJ, Brasil *Departamento de Patologia **Laboratório de Helmintos

Parasitos de Vertebrados, Departamento de Helmintologia, Instituto Oswaldo Cruz-Fiocruz Rio de Janeiro, RJ, Brasil

Schistosoma mansoni adult worms with genital anomalies isolated from Nectomys squamipes (Muridae: Sigmodontinae) were studied by confocal laser scanning microscopy under the reflected mode. One male without testicular lobes (testicular agenesia/anorchism) and two females, one with an atrophied ovary and another with 17 uterine eggs, were identified. The absence of testicular lobes occurred in a worm presenting otherwise normal male adult characteristics: tegument, tubercles and a gynaecophoric canal with spines. In both female specimens the digestive tube showed a vacuolated appearance, and the specimen with supernumerary uterine eggs exhibited a developing miracidium and an egg with a formed shell. The area of the ventral sucker was similar in both specimens however the tegument thickness, ovary and vitelline glands of the specimen with the atrophied ovary were smaller than those of the one with supernumerary eggs. These reported anomalies in the reproductive system call attention to the need to improve our understanding of genetic regulation and the possible role of environmental influences upon trematode development.

Key words: Schistosoma mansoni - reproductive system abnormalities - adult worms - trematode - anorchism confocal laser scanning microscopy

The somatic development and reproductive system of adult worms of Schistosoma mansoni suffer intense selective pressure from the vertebrate hosts. Full somatic development of adult worms, characterized by large size, complete formation of reproductive organs and complete tegumental maturation, is reached only in permissive hosts (mice, hamster and water rat) (Cioli et al. 1977, MachadoSilva et al. 1997). However, anomalous specimens can occur sporadically even in favorable hosts. In this context, Najim (1951) found a male adult with two sets of testes, which he considered as supranumerary testes. Machado Filho (1966) recovered a female with six uterine eggs, without however any visible morphological alterations. Dias and Ribeiro (1980) found in S. mansoni eggs containing two active miracidia the feces from a patient.

This article describes morphologically the abnormalities of the reproductive system of $S$. mansoni adult worms (two females and one male) isolated from Nectomys

This work was sponsored by Universidade do Estado do Rio de Janeiro (Uerj) and Fundação Oswaldo Cruz (Fiocruz) and is part of a Master Thesis, Instituto de Biologia, Uerj, RJ, Brazil. ${ }^{+}$Corresponding author. Fax: +55-21-2587.6112. E-mail: machado@uerj.br.

${ }^{++} \mathrm{CNPq}$ Research fellows

Received 16 September 2002

Accepted 9 January 2003 squamipes (Muridae: Sigmodontinae), which is a permissive host, using brightfield and confocal laser scanning microscopies.

\section{MATERIALS AND METHODS}

The study was based on an examination of anomalous adult $S$. mansoni specimens, obtained from the mesenteric veins of nine-week-old $N$. squamipes, presenting the following characteristics: one male without testicular lobes and two females, one with an atrophied ovary and another with 17 uterine eggs. The animal, from which the male specimen was obtained, was infected with cercariae from Biomphalaria glabrata infected with a Brazilian $S$. mansoni strain (CM) isolated from a patient in the municipality of São Lourenço da Mata (Recife, State of Pernambuco). The anomalous females came from another $N$. squamipes infected with cercariae belonging to a strain isolated from Rattus rattus, maintained in Brazilian $B$. glabrata and originating from Guadaloupe (Antilles) (GD strain). After conventional perfusion, the worms were fixed in AFA (acetic acid, formaldeyde and alcohol 95\%), stained with chloride carmine, cleared in methyl salicylate and assembled on glass slides (Neves et al. 1998). Voucher specimens were deposited in the Helminthological Collection of the Instituto Oswaldo Cruz (CHIOC: 34771a, 34771b, 34772), Rio de Janeiro, Brazil. Digital images were obtained using a brightfield microscope (Olympus, BX 50) linked to image analysis software (Image Pro Plusversion 3.0, Media Cybernetics, USA) and were used for morphometric evaluation of the following measurements: 
area of the suckers and distance between them; area, smaller and larger diameters and perimeter of uterine eggs and egg spine area. From acquired confocal images (LSM410, Zeiss), using a $543 \mathrm{~nm} \mathrm{He} / \mathrm{Ne}$ laser and a LP 570 filter under reflected mode, the thickness of the tegument under the ventral sucker of the three specimens, the width and length of the ovary and vitelline glands were measured by specific software (version 3.98, Zeiss) pertaining to the equipment.

Normal adult worms were isolated from experimentally infected $N$. squamipes with the same strains under the same conditions, and were used as controls.

\section{RESULTS}

For the male specimen the morphometric values were: $22056 \mu \mathrm{m}^{2}$ for the area of the oral sucker, $19831 \mu \mathrm{m}^{2}$ for the ventral sucker, $255 \mu \mathrm{m}$ for the distance between them and $11 \mu \mathrm{m}$ for the thickness of the tegument. Testicular lobes were not identified, even after virtual tomography under reflected mode by confocal laser scanning microscopy (CLSM). However, the specimen presented other male adult characteristics such as a fully developed tegu- ment, tubercles with spines and a gynaecophoric canal (Fig. 1). In contrast, the confocal analysis of the corresponding body segment from normal adult males clearly developed testicular lobes and a seminal vesicle (Fig. 2).

In females worms the atrophy of the ovary observed by brightfield microscopy in one specimen was also confirmed by CSLM (Fig. 3), contrasting with the regular ovary of normal females (Fig. 4). The supernumerary uterine eggs seen in another specimen exhibited a miracidium in developmental stage and an egg with a formed shell (Fig. 5). In both female specimens the digestive tube was deformed by large dilatations of the lumen, containing amorphous and vacuolated material (Fig. 6). The comparison between the anomalous females, except for the area of the ventral sucker, showed that the specimen with atrophied ovary showed smaller measurements than the female with supranumerary eggs (Tables I, II).

\section{DISCUSSION}

The actual incidence of dysmorphogenetic defects among $S$. mansoni adult worms is completely unknown. However it has been established that this incidence may

TABLE I

Comparative measurements between anomalous and normal Schistosoma mansoni females isolated from Nectomys squamipes (GD strain), using brightfield microscopy

\begin{tabular}{|c|c|c|c|}
\hline & Atrophied ovary & Supranumerary eggs & Normal females ${ }^{b}$ \\
\hline \multicolumn{4}{|l|}{ Suckers } \\
\hline Area oral sucker $\left(\mu \mathrm{m}^{2}\right)$ & 1810.0 & 2621.0 & 2190.1 \\
\hline Area ventral sucker $\left(\mu \mathrm{m}^{2}\right)$ & 1911.0 & 1871.0 & 2112.4 \\
\hline Distance between suckers $(\mu \mathrm{m})$ & 89.0 & 161.0 & 160.0 \\
\hline \multicolumn{4}{|l|}{$\operatorname{Egg}^{a}$} \\
\hline Area $\left(\mu \mathrm{m}^{2}\right)$ & - & 1923.0 & 2698.0 \\
\hline Larger diameter $(\mu \mathrm{m})$ & - & 70.0 & 97.0 \\
\hline Smaller diameter $(\mu \mathrm{m})$ & - & 33.7 & 34.0 \\
\hline Perimeter $(\mu \mathrm{m})$ & - & 186.3 & 246.0 \\
\hline \multicolumn{4}{|l|}{ Egg spine } \\
\hline Area $\left(\mu \mathrm{m}^{2}\right)$ & - & 133.3 & 121.5 \\
\hline Larger diameter $(\mu \mathrm{m})$ & - & 17.7 & 17.0 \\
\hline Smaller diameter $(\mu \mathrm{m})$ & - & 8.7 & 8.0 \\
\hline Perimeter $(\mu \mathrm{m})$ & - & 50.3 & 49.4 \\
\hline
\end{tabular}

$a$ : the mean of three eggs; - not detected; $b$ : mean $(\mathrm{n}=15)$

TABLE II

Comparative measurements between anomalous and normal Schistosoma mansoni females isolated from Nectomys squamipes, using confocal scanning laser microscopy

\begin{tabular}{lcrr}
\hline & Atrophied ovary & Supranumerary eggs & Normal female $^{b}$ \\
\hline Tegument & & & \\
$\quad$ Thickness $(\mu \mathrm{m})$ & 4.9 & 6.8 & 4.5 \\
Ovary & & & 25398.0 \\
$\quad$ Area $\left(\mu \mathrm{m}^{2}\right)$ & 3313.0 & 4931.0 & 306.0 \\
Length $(\mu \mathrm{m})$ & 92.9 & 114.1 & 83.0 \\
Width $(\mu \mathrm{m})$ & 48.4 & 56.9 & 483.0 \\
Vitelline glands $^{2}$ & & 825.0 & 41.0 \\
Area $\left(\mu \mathrm{m}^{2}\right)$ & 85.4 & 40.6 & 13.0 \\
Length $(\mu \mathrm{m})$ & 14.7 & 21.2 & \\
Width $(\mu \mathrm{m})$ & 7.6 & & \\
\hline
\end{tabular}

$a$ : mean of $\mathrm{n}=5$ (female with atrophied ovary) and $\mathrm{n}=8$ (female with supranumerary eggs); $b$ : mean $(\mathrm{n}=15)$ 

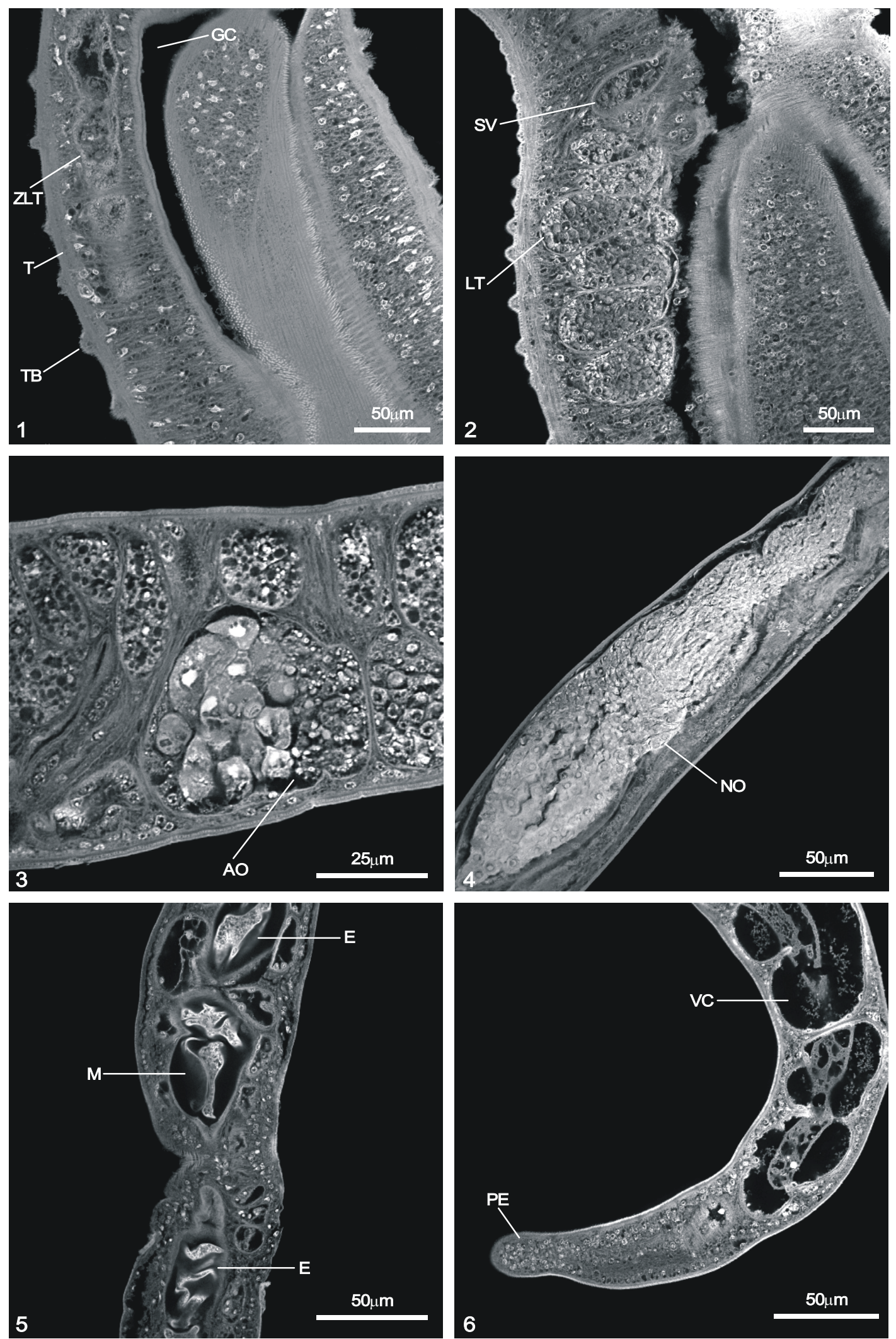

Reproductive system abnormalities in Schistosoma mansoni (confocal laser scanning microscopy) - Fig. 1: adult male with anorchism. The mark indicates the zone where the testis use to be. ZLT: zone without testicular lobes; T: tegument; TB: tubercle; CG: gynaecophoric canal. Fig. 2: normal adult male with testis consisting of seven lobes (LT), close to seminal vesicle (SV). Fig. 3: female with atrophied ovary (AO) showing oocytes in different stages of development. Fig. 4: normal adult female with normal ovary (NO). Fig. 5: female with dilated uterus with supranumerary eggs presenting miracidium (M) in maturation process and defined eggshell. Fig. 6: female with dilated intestinal lumen, containing amorphous and vacuolated material (VC). PE: posterior end 
vary according to host, environmental/teratogenic factors, including drugs, polygenic disorders, single gene mutations and others (Thorogood 1997).

$S$. mansoni is a dioecious trematode, as a result of evolutive pressure, acquired different and complementary functions where the males became oriented to fecundation (Basch 1990, Platt \& Brooks 1997) and female transportation to the site of oviposition, which is facilitated by the complex musculature of the suckers (Mair et al. 2000, Morand \& Muller-Graf 2000), while the females invested in the production of eggs (Morand \& Muller-Graf 2000). Therefore, any imbalance in this relationship can affect the reproduction of this parasitic flatworm. In female schistosomes, an intimate and permanent association with the male is necessary for reproduction to occur (Kunz 2001).

The finding of atypical adult worms collected from permissive hosts with alterations in the location of the testicular lobes has already been reported (Najim 1951, Machado-Silva et al. 1994, Neves et al. 1998). In the present article, we described a male specimen without testicular lobes (testicular agenesia), not related to immature stage (below 21-days-old). Although sexual maturation without synchronism can occur (Barbosa et al. 1978), in our experiment, the hosts were with nine weeks post infection, time enough for all the specimens of the entire population to reach the adult stage. Furthermore, the tegument of the male with testicular agenesia had tubercles and its thickness was compatible with that of adult stage (Machado-Silva et al. 1994, 1997, 1998, Neves et al. 1998). Finally, it is worthwhile to point out that young specimens (21 days old) already present two testicular lobes (Clegg 1965).

Structural modifications of the female reproductive system can occur during maintenance of the trematode in vitro (Basch 1981) or in unisexual infections (Erasmus 1973). In the present experiment, alterations were evidenced in mixed infections. One of the females of the GD strain presented atrophy in both ovary and vitelline glands. Other components of the reproductive system (oviduct, ootype, uterus) presented normal aspect, resembling those of immature females derived from unisexual infection (Erasmus 1973). After 63 days of infection, it is not expected to find immature females, considering that the immature sexual stages appear only during the morphogenetic period (30-38 days) (Popiel 1986). Conversely, the preservation of the reproductive morphogenesis is determined by the permanent pairing of specimens (LoVerde \& Chen 1991, Southgate et al. 1998), which depends on the sex ratio between them. In the present article this ratio was balanced $(1: 1)$, which lead us to assume that all specimens were paired, even though it has been demonstrated that males are not monogamous (PicaMattocia et al. 2000). According to Kunz (2001), the male signal does not differentiate pluripotent stem cells into germ cells. Instead, it regulates the multiplication and differentiation of germ cells that are already present, located in separate organs and committed to become oocytes or vitellocytes before pairing with a male. Vitelline cells are haploid, suggesting a common origin of the vitelline gland and ovary. In S. mansoni cultured in vitro from cercariae to adults, vitelline cells are essentially normal, demon- strating that specific host influences are not necessary for their development (Basch \& Samuelson 1990).

Another female derived from the same strain was also atypical, presenting supernumerary eggs and intestinal dilatation. This situation is rare and confirms a previous report of a specimen with six supranumerary eggs (Machado Filho 1966). Morphological alterations have not been evidenced in the other components of the reproductive system, and the eggs were inside a dilated uterus. This observation, together with the fact that the eggs were mature, with miracidium and configurated shell, and the intestinal and uterus lumens were dilated, suggested that the main reason was egg intrauterine retention by unknown obstructive mechanism, rather than egg production and or secretion defects. The intestinal and uterine lumen dilatation may also have been due to impaired or insufficient female musculature. Female reproductive changes could be partially related to intestinal enzymatic deficiencies, since products of hemoglobin digestion by intestinal hemoglobinases are shuttled into the vitellaria, where they serve as egg yolk for the soon-to-develop miracidium (Newport \& Agabian 1990).

In our experiment, even considering that the strains are different, they had also been maintained in the laboratory and, moreover, other analyzed specimens did not present alterations similar to those presently described. As the same intermediate and definitive hosts were utilized for both strains, we consider that these strains were under the same selective pressure.

The scientific communication of these types of rare development anomalies or defects, expressing phenotypic variations will undoubtedly help to improve our understanding of the molecular, genetic and cellular mechanisms underlying normal development in parasitic helminthes.

\section{REFERENCES}

Barbosa MA, Pellegrino J, Celho PM, Sampaio IB 1978. Quantitative aspects of the migration and evolutive asynchronism of Schistosoma mansoni in mice. Rev Inst Med Trop São Paulo 20: 121-132.

Basch PF 1981. Cultivation of Schistosoma mansoni in vitro. II. Production of infertile eggs by worm pairs cultured from cercariae. J Parasitol 67: 186-190.

Basch PF 1990. Why do schistosomes have separate sexes? Parasitol Today 6: 160-163.

Basch PF, Samuelson J 1990. Cell biology of schistosomes. I. Ultrastructure and transformations. In Modern Parasite Biology. Cellular, Immunological and Molecular Aspects, WH Freeman and Co., New York, p. 91-106.

Cioli D, Knopf PM, Senft AW 1977. A study of Schistosoma mansoni transferred into permissive and nonpermissive hosts. Int J Parasitol 7: 293-297.

Clegg JA 1965. In vitro cultivation of Schistosoma mansoni. Exp Parasitol 16: 133-147.

Dias LC, Ribeiro OB 1980. Schistosoma mansoni: eggs with two miracidia. Trans R Soc Trop Med Hyg 74: 826.

Erasmus DA 1973. A comparative study of the reproductive system of mature, immature and " unisexual" female Schistosoma mansoni. Parasitology 67: 165-183.

Kunz W 2001. Schistosome male-female interaction: induction of germ-cell differentiation. Trends Parasitol 17: 227-231.

LoVerde PT, Chen L 1991. Schistosome female reproductive development. Parasitol Today 7: 303-308. 
Machado Filho BA 1966. Sobre uma fêmea de Schistosoma mansoni Sambon, 1907 com seis ovos "in útero". Atas Soc Biol Rio de Janeiro 10: 11-12.

Machado-Silva JR, Galvão C, Presgrave OAF, Rey L, Gomes DC 1994. Host-induced morphological changes of Schistosoma mansoni Sambon, 1907 male worms. Mem Inst Oswaldo Cruz 89: 411-416.

Machado-Silva JR, Lanfredi RM, Gomes DC 1997. Morphological study of adult male worms of Schistosoma mansoni by scanning electron microscopy. Mem Inst Oswaldo Cruz 92: 647-653.

Machado-Silva JR, Pelajo-Machado M, Lenzi HL, Gomes DC 1998. Morphological study of adult male worms of Schistosoma mansoni Sambon, 1907 by confocal laser scanning microscopy. Mem Inst Oswaldo Cruz 93: 303-307.

Mair GR, Maule AG, Day TA, Halton DW 2000. A confocal microscopical study of the musculature of adult Schistosoma mansoni. Parasitology 121: 163-170.

Morand S, Muller-Graf CD 2000. Muscles or testes? Comparative evidence for sexual competition among dioecious blood parasites (Schistosomatidae) of vertebrates. Parasitology 120: 45-56.

Najim AT 1951. A male Schistosoma mansoni with two sets of testes. J Parasitol 37: 545-546.
Neves RH, Pereira MJS, Gomes DC, Oliveira RMF, MachadoSilva JR 1998. Morphometric differences of adult worms from sympatric samples of Schistosoma mansoni Sambon, 1907 isolated from rodents and humans. Mem Inst Oswaldo Cruz 93: 309-312.

Newport GR, Agabian N 1990. Molecular biology of schistosomes and filariae. In Modern Parasite Biology. Cellular, Immunological and Molecular Aspects, WH Freeman and Co., New York, p. 362-383.

Pica-Mattocia L, Moroni R, Tchuem Tchuente LA, Southgate VR, Cioli D 2000. Changes of mate occur in Schistosoma mansoni. Parasitology 120: 495-500.

Platt TR, Brooks DR 1997. Evolution of the schistosomes (Digenea: Schistosomatoidea): the origin of dioecy and colonization of the venous system. J Parasitol 83: 1035-1044.

Popiel I 1986. Male-stimulated female maturation in Schistosoma: a review. J Chem Ecol 12: 1745-1754.

Southgate VR, Jourdane J, Tchuente LA 1998. Recent studies on the reproductive biology of the schistosomes and their relevance to speciation in the Digenea. Int J Parasitol 28: 1159-1172.

Thorogood P 1997. The relationship between genotype and phenotype: some basic concepts. In Embryos, Genes and Birth Defects, John Wiley \& Sons Ltd, England, p. 1-16. 
Reproductive Abnormalities in S. mansoni - Renata Heisler Neves et al. 